\title{
Efektifitas Massage Counter Pressure Pada Nyeri Persalinan Kala I Fase Aktif
}

\author{
Luh Putu Ani Widiyastiti ${ }^{1}$, Kartika Sari ${ }^{2}$ \\ ${ }^{1,2}$ Program Studi Kebidanan Program Sarjana, Universitas Ngudi Waluyo \\ Semarang \\ Email: widiyastitiani@gmail.com,kartikanaka@gmail.com
}

\begin{abstract}
ABSTRAK
Nyeri persalinan merupakan pengalaman subjektif tentang sensasi fisik yang terkait dengan kontraksi uterus, dilatasi dan penipisan serviks, serta penurunan janin selama persalinan. Kondisi Nyeri yang hebat pada kala I persalinan memungkinkan para ibu cenderung memilih cara yang paling gampang dan cepat untuk menghilangkan rasa nyeri. Upaya yang dapat dilakukan untuk mengatasi nyeri persalinan Kala I adalah dengan metode non farmakologis salah satunya dengan massage counter pressure. Untuk mengetahui perbedaan nyeri sebelum dan sesudah massage counter pressure pada nyeri persalinan kala I Fase Aktif. Jenis penelitian yang digunakan adalah quasi eksperimen dengan rancangan one group pretest dan posttest desgn. Metode pengambilan sampel secara accidental sampling dengan jumlah sampel 15 orang. Analisis uji statistik menggunakan Dependent TTest. Rata-rata nyeri persalinan sebelum dilakukan massage counter pressure adalah 3.600 dengan standar deviasi 0.507 dan setelah dilakukan massage counter pressure nilai nyeri responden yaitu 2.666 dengan standar deviasi 0.617 , terlihat adanya perbedaan nilai atau penurunan sebelum dan sesudah dilakukan massage counter pressure yaitu 0.933 dengan standar deviasi 0.258 serta hasil uji statistik didapatkan $\mathrm{p}=0.000$. Ada perbedaan yang signifikan antara nyeri sebelum dan sesudah dilakukan massage counter pressure di Alin's Medical Clinic. Diharapkan petugas kesehatan terutama bidan dapat memberikan massage counter pressure pada ibu bersalin agar dapat mengurangi angka morbiditas dan mortalitas pada ibu.
\end{abstract}

\section{Kata Kunci: Massage Counter Pressure, Nyeri Persalinan}

\section{ABSTRACT \\ Effectiveness of Counter Pressure Massage In Active Phase I Labor Pain}

Labor pain is a subjective experience of physical sensations associated with uterine contractions, cervical dilation and thinning, and fetal decline during labor. Severe pain condition during the first stage of labor allows mothers to tend to choose the easiest and fastest way to relieve pain. Efforts that can be made to deal with the first stage of labor pain are non-pharmacological methods, one of which is counter pressure massage. To determine the difference in pain before and after counter pressure massage in the active phase I labor pain. This type of research is a quasiexperimental design with a pretest and posttest control group design. The sampling method was accidental sampling with a sample size of 15 people. Statistical test analysis using Dependent T-Test. The average labor pain before counter pressure massage was 3,600 with a standard deviation of 0.507 and after counter pressure massage the respondent's pain value was 2,666 with a standard deviation of 0.617,

Efektifitas Massage Counter... Luh Putu Ani Widiyastiti, Kartika Sari Journal of Holistics and Health Sciences Vol. 3, No. 2 September 2021 
it was seen that there was a difference in value or decrease before and after the counter pressure massage was carried out, namely 0.933 with standard deviation of 0.258 and the statistical test results obtained $p=0.000$. There was a significant difference between pain before and after counter pressure massage at Alin's Medical Clinic. It is hoped that health workers, especially midwives, can provide counter pressure massage to mothers who give birth in order to reduce morbidity and mortality in

mothers.

\section{Keywords: Massage Counter Pressure, Labor Pain}

\section{PENDAHULUAN}

Persalinan dan kelahiran merupakan kejadian fisiologi yang normal dalam kehidupan. Persalinan normal merupakan proses pengeluaran hasil konsepsi yang sudah aterm berupa janin dengan presentasi belakang kepala, kemudian disusul dengan pengeluaran plasenta dan selaput ketuban dari jalan lahir yang lahir secara spontan tanpa komplikasi (Nurasiah, 2014).

Nyeri persalinan adalah suatu pengalaman seseorang tentang sensasi tubuhnya yang berkaitan dengan his atau kontraksi otot rahim yang menimbulkan pembukaan dan penipisan mulut rahim sehingga kepala janin turun selama proses persalinan (Utami, 2019).

Upaya yang bisa diterapkan dalam mengurangi nyeri persalinan Kala I adalah dengan metode non farmakologis salah satunya adalah massage counter pressure, caranya pasien dalam kondisi duduk atau tidur miring ke kiri selanjutnya bidan atau keluarga pasien menekan sacrum secara bergantian menggunakan kepalan tangan secara mantap dan beraturan. Metode ini sangat efektif karena penekanannya dilakukan di daerah paling nyeri (pusat nyeri) yang dirasakan oleh ibu bersalin yaitu daerah punggung atau sacrum, sehingga mampu mengurangi rasa nyeri saat kontraksi ibu bersalin kala I (Utami, 2019).
Berdasarkan

studi pendahuluan yang dilakukan, pada ibu inpartu belum pernah dilakukan metode massage counter pressure. Oleh sebab itu, peneliti ingin melakukan penelitian tentang "Efektifitas Massage Counter Pressure pada Nyeri Persalinan Kala I Fase Aktif'.

\section{METODE}

Jenis penelitian yang digunakan adalah quasi eksperimen dengan rancangan one group pretest dan posttest design, menggunakan pendekatan cross sectional untuk melihat apakah ada perbedaan sebelum dan setelah perlakuan. Penelitian ini dilaksanakan di Alin's Medical Medical Kabupaten Badung dari tanggal 1 November sampai 15 Desember 2020. Populasi penelitian ini adalah $22 \mathrm{ibu}$ bersalin yang datang pada tanggal penelitian. Proses pengambilan sampel menggunakan teknik accidental sampling, dimana responden diambil secara kebetulan yang tersedia di tempat penelitian (Notoatmodjo, 2012). Jumlah sampel yang didapatkan sebanyak 15 orang yang diambil dari tanggal 1 November sampai 15 Desember 2020, 7 orang lainnya tidak sesuai dengan kriteria dimana ibu datang pada pembukaan lengkap dan ada yang dirujuk.

Analisis univariat menggunakan tabel distribusi frekuensi dengan bantuan 
program SPSS dan pada analisis bivariat menggunakan uji statistik Dependent T-Test dengan tingkat kepercayaan $95 \%$, tingkat kesalahan $5 \%$. Sebelum ke uji dependent t-test, dilakukan dulu uji normalitas data, 1. Analisis Univariat karena sampel kurang 30 orang maka dilakukan uji normalitas data dengan Shapiro-Wilk.

\section{HASIL DAN PEMBAHASAN \\ HASIL}

a. Karateristik Responden

1) Umur

Tabel 1 Distribusi Frekuensi Umur Responden

\begin{tabular}{lll}
\hline \multicolumn{1}{c}{ Umur } & \multicolumn{1}{c}{ Frekuensi $(\mathrm{F})$} & \multicolumn{1}{c}{ Presentase $(\%)$} \\
\hline$<20$ Tahun & 2 & 13.3 \\
20-35 Tahun & 12 & 80.0 \\
>35 Tahun & 1 & 6.7 \\
\hline Jumlah & 15 & 100.0 \\
\hline
\end{tabular}

Berdasarkan tabel di atas dapat dilihat bahwa jumlah responden sebanyak 15 orang dengan mayoritas umur 20-35 tahun sebanyak 12 orang $(80,0 \%)$, paling rendah umur responden yaitu $>35$ tahun sebanyak 1 orang $(6,7 \%)$ dan sisanya berumur $<20$ tahun sebanyak 2 orang $(13,3 \%)$.

2) Pendidikan

Tabel 2 Distribusi Frekuensi Pendidikan Responden

\begin{tabular}{lll}
\hline \multicolumn{1}{c}{ Pendidikan } & Frekuensi $(\mathrm{F})$ & \multicolumn{1}{c}{ Presentase $(\%)$} \\
\hline Dasar & 3 & 20.0 \\
Menengah & 9 & 60.0 \\
Tinggi & 3 & 20.0 \\
\hline Jumlah & 15 & 100.0 \\
\hline
\end{tabular}

\begin{tabular}{|c|}
\hline \\
\hline \\
\hline \\
\hline \\
\hline \\
\hline \\
\hline \\
\hline \\
\hline \\
\hline Pada tabel \\
\hline
\end{tabular}

pendidikan terakhir responden paling rendah yaitu pendidikan rendah dan pendidikan tinggi masing-masing sebanyak 3 orang $(20,0 \%)$.

3) Pekerjaan

Tabel 3 Distribusi Frekuensi Pekerjaan Responden

\begin{tabular}{|c|c|c|}
\hline Pekerjaan & Frekuensi (F) & Presentase (\%) \\
\hline IRT & 3 & 20.0 \\
\hline Petani & 6 & 40.0 \\
\hline Wiraswasta & 6 & 40.0 \\
\hline Jumlah & 15 & 100.0 \\
\hline
\end{tabular}

Pada tabel 3 pekerjaan responden paling tinggi sebagai petani dan wiraswata yaitu masing-masing sebanyak
6 orang $(40,0 \%)$, dan paling rendah sebagai ibu rumah tangga sebanyak 3 orang $(20,0 \%)$. 
4) Paritas

Tabel 4 Distribusi Frekuensi Paritas Responden

\begin{tabular}{lll}
\hline \multicolumn{1}{c}{ Paritas } & Frekuensi (F) & \multicolumn{1}{c}{ Presentase (\%) } \\
\hline Primipama & 6 & 40.0 \\
Multipara & 8 & 53.3 \\
Grande Multipara & 1 & 6.7 \\
\hline Jumlah & 15 & 100.0 \\
\hline & & \\
Pada tabel 4 & rendah \\
grandemultipara yaitu 1 \\
orang (6,7\%), sisanya \\
primipara sebanyak 6 \\
orang (40,0\%).
\end{tabular}

b. Nyeri Sebelum dilakukan Massage Counter Pressure

Table 5 Distribusi Frekuensi Nyeri Responden Sebelum diberikan

\begin{tabular}{lll}
\multicolumn{3}{c}{ Massage Counter Pressure } \\
\hline \multicolumn{1}{c}{ Tingkat Nyeri } & Frekuensi (F) & \multicolumn{1}{c}{ Presentase (\%) } \\
\hline Nyeri Sedang & 6 & 40.0 \\
Nyeri Berat & 9 & 60.0 \\
Total & 15 & 100.0 \\
\hline
\end{tabular}

Dari tabel 5 dapat dilihat bahwa nyeri persalinan sebelum dilakukan massage counter pressure paling tinggi mengalami nyeri berat yaitu

c. Nyeri Sesudah dilakukan Massage Counter Pressure

Table 6 Distribusi Frekuensi Nyeri Responden Sesudah di berikan Massage Counter Pressure

\begin{tabular}{lll}
\hline \multicolumn{1}{c}{ Tingkat Nyeri } & \multicolumn{1}{c}{ Frekuensi (F) } & \multicolumn{1}{c}{ Presentase (\%) } \\
\hline Nyeri Ringan & 6 & 40.0 \\
Nyeri Sedang & 8 & 53.3 \\
Nyeri Berat & 1 & 6.7 \\
Total & 15 & 100.0 \\
\hline
\end{tabular}

Dari tabel 6 menunjukan bahwa setelah diberikan massage counter pressure tingkat nyeri responden paling tinggi

2. Analisis Bivariat

Tabel 7 Distribusi Uji Normalitas Data Responden di Alin's Medical Clinic Kab.

Badung

Tests of Normality

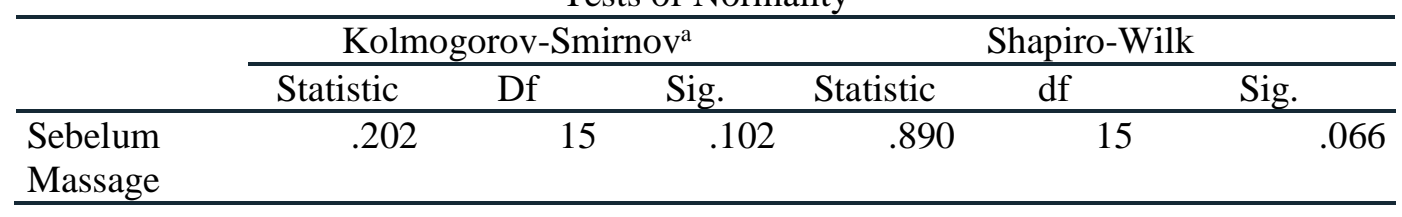

mengalami nyeri sedang yaitu 8 orang $(53,3 \%)$, paling rendah nyeri berat 1 orang $(6,7 \%)$, sisanya mengalami nyeri ringan sebanyak 6 orang $(40,0 \%)$. berjumlah 9 orang $(60,0 \%)$ dan pedang rerjumlah 6 orang $(40,0 \%)$. 


\begin{tabular}{lllllll}
\hline $\begin{array}{l}\text { Setelah } \\
\text { Massage }\end{array}$ & .172 & 15 & $.200^{*}$ & .939 & 15 & .373 \\
\hline
\end{tabular}

Bedasarkan tabel 7 uji normalitas data menggunakan Shapiro-Wilk karena jumlah responden $<30$, didapatkan nilai signifikansi sebelum massage adalah 0,066 dan setelah massage
0,373, hal tersebut menunjukan bahwa nilai signifikansi >0,05 yang menyatakan bahwa data di atas berdistribusi normal dan bisa dilanjutkan dengan uji dependent $t$ test.

Table. 8 Distribusi Perbedaan Nyeri Sebelum dan Sesudah Massage Counter Pressure pada Nyeri Persalian Kala I Fase Aktif

Paired Samples Statistics

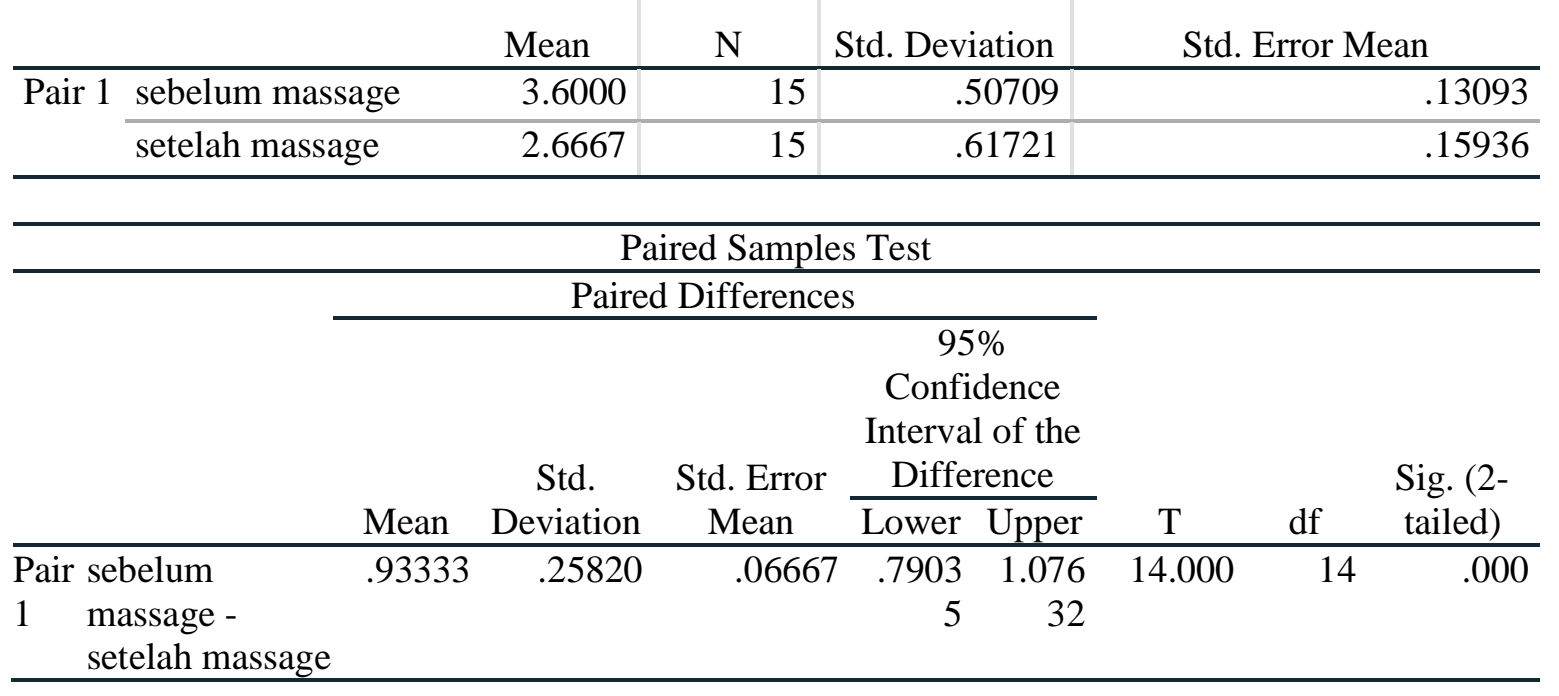

Berdasarkan tabel 7 di atas rata-rata nyeri responden sebelum massage counter pressure adalah 3,600 dengan standar deviasi 0,507 dan sesudah dilakukan massage counter pressure nilai nyeri responden yaitu 2,666 dengan standar deviasi 0,617. Hal ini menunjukan ada perbedaan nilai atau penurunan sebelum dan sesudah dilakukan massage counter pressure yaitu 0,933 dengan standar deviasi 0,258 . Hasil uji statistik didapatkan $\mathrm{p}=0,000$ maka bisa disimpulkan ada perbedaan signifikan antara sebelum dilakukan massage counter pressure dengan sesudah dilakukan massage counter pressure di Alin's Medical Clinic.

\section{PEMBAHASAN}

1. Nyeri Ibu Bersalin Kala I Fase Aktif Sebelum dilakukan Massage Counter Pressure

Sebelum $\begin{array}{r}\text { dilakukan } \\ \text { massage counter pressure } \\ \text { responden paling banyak }\end{array}$
mengalami nyeri berat yang
berjumlah 9 orang $(60,0 \%)$ dan
paling rendah nyeri sedang yang
berjumlah 6 orang $(40,0 \%)$.
Hal yang menyebabkan
ibu bersalin mengalami nyeri
berat, dikarenakan responden


banyak dari ibu yang akan melahirkan anak pertama (primipara). Nyeri persalinan pada primipara seringkali lebih berat dibandingkan ibu multipara, karena pada multipara penipisan serviks biasanya berbarengan dengan dilatasi serviks, sedangkan ibu primipara dilatasi serviksnya terjadi belakangan dan penipisan serviks yang terjadi lebih dahulu. Intensitas kontraksi uterus yang dirasakan pada primipara pun lebih besar daripada multipara, terutama pada akhir kala I dan permulaan Kala II persalinan (Yuliatun, 2013).

$$
\text { Menurut penelitian }
$$

Afritayenu (2017), umur dapat menjadi salah satu faktor tingkat nyeri ibu bersalinan, maksudnya ibu yang berumur muda $(<20$ tahun) akan timbul rasa kecemasan karena mengalami proses persalinan yang pertama dalam hidupnya. Begitu juga yang terjadi pada ibu bersalin berumur tua (> 35 tahun) bisa mengakibatkan kecemasan karena umur yang sudah beresiko. Bila kecemasan meningkat dapat pula meningkatkan rasa nyeri persalinan.

Mayoritas pendidikan responden adalah SMA dan sedikit yang berpendidikan tinggi. Menurut penelitian Siregar (2019), pendidikan berpengaruh terhadap pengetahuan ibu tentang proses persalinan, nyeri persalinan dan cara mengatasi nyeri. Ibu yang mempunyai pengetahuan yang bagus terhadap proses persalinan dan cara mengatasi nyeri dapat membuat ibu mampu mengontrol nyeri yang dirasakannya.

2. Nyeri Ibu Bersalin Kala I Fase Aktif Sesudah dilakukan Massage Counter Pressure

Berdasakan hasil penelitian terjadi penurunan tingkat nyeri sesudah dilakukan massage counter pressure, dari 15 responden mayoritas responden mengalami nyeri sedang berjumlah 8 orang $(53,3 \%)$, sisanya mengalami nyeri ringan berjumlah 6 orang $(40,0 \%)$ dan nyeri berat 1 orang (6,7\%). Data tersebut menunjukan sesudah diberikan massage counter pressure banyak responden yang nyerinya berkurang, dimana dari 9 orang respnden yang mengalami nyeri berat nyerinya berkurang menjadi nyeri sedang sebanyak 8 orang, dari 6 orang reponden yang mengalami nyeri sedang nyerinya berkurang menjadi nyeri ringan dan ada 1 responden yang mengalami nyeri tetap yaitu nyeri berat.

Nyeri tetap yang dialami responden ini disebabkan karena pembukaan sudah $8 \mathrm{~cm}$ atau di akhir kala I fase aktif, dimana nyeri responden sudah terpusat di daerah vulva dan perineum karena penurunan kepala janin (Yuliatum, 2013).

$$
\text { Responden yang }
$$

mengalami penurunan nyeri disebabkan karena massage counter pressure pada ibu bersalin dapat meringankan kram dan ketegangan pada otot tulang paha maupun tulang panggul, menurunkan nyeri serta mampu mempercepat proses persalinan (Yuliatun, 2013). 
3. Perbedaan Nyeri Sebelum dan Sesudah Massage Counter Pressure pada Nyeri Persalinan Kala I Fase Aktif

Berdasarkan hasil dari uji dependent $t$-test yang dilakukan rata-rata nyeri ibu bersalin sebelum dilakukan massage counter pressure adalah 3,600 dengan standar deviasi 0,507 dan setelah dilakukan massage counter pressure nilai nyeri responden yaitu 2,666 dengan standar deviasi 0,617 , terlihat adanya perbedaan nilai atau penurunan sebelum dan sesudah dilakukan massage counter pressure yaitu 0,933 dengan standar deviasi 0,258 serta hasil uji statistik didapatkan $\mathrm{p}=0.000$ sehingga bisa disimpulkan bahwa ada perbedaan yang signifikan antara sebelum dilakukan massage counter pressure dengan setelah dilakukan massage counter pressure di Alin's Medical Clinic.

Hasil penelitian ini sejalan dengan penelitian yang dilakukan oleh Endah Yulianingsih, Hasnawatty Surya Porouw dan Suwarni dengan judul "Teknik Massage Counter Pressure terhadap Penurunan Intensitas Nyeri Kala 1 Fase Aktif pada Ibu Bersalin di RSUD. Dr. M.M Dunda Limboto Kabupaten Gorontalo", memberikan hasil bahwa nyeri persalinan kala I fase aktif sebelum massage countre pressure adalah dengan tingkat nyeri berat sebanyak $50 \%$, sesudah dilakukan massage countre pressure tingkat nyeri sedang sebanyak $45 \%$ dan hasil uji statistik menyatakan $p$ value $0,000<\alpha$ 0.05. Hal ini menyatakan bahwa massage counter pressure berpengaruh terhadap nyeri persalinan kala I fase aktif dan ada perbedaan yang signifikan antara sebelum dengan sesudah massage counter pressure di RSUD. MM Dunda Limbota (Yulianingsih, 2019).

Penelitian ini juga sejalan dengan penelitian Hadriani dan Eka Purwaningsih dengan judul "Pengaruh Massage Counter Pressure terhadap Nyeri Persalinan Kala I Fase Aktif pada Ibu Bersalin Di BPM Setia", yang menyatakan nyeri persalinan kala I fase aktif sebelum massage counter pressure sebagian besar mengalami nyeri berat yaitu 9 responden $(60,0 \%)$, sedangkan sesudah dilakukan massage counter sebagian besar responden mengalami nyeri sedang yaitu 9 responden $(60,0 \%)$. Hasil uji statistik juga menyatakan nilai $p$-value $=0,000$ yang menunjukan massagse counter pressure berpengaruh tehadap nyeri ibu bersalin kala I fase aktif dan ada perbedaan yang signifikan antara sebelum dengan sesudah massage counter pressure di BPM Setia (Hadriani, 2018).

Hasil penelitian ini juga didukung oleh penelitian yang dilakukan oleh Seri Pasongli, maria ranting, Ellen pasak, penelitian yang berjudul "Efektifitas Counter Pressure terhadap Penurunan Intensitas Nyeri Kala I Fase Aktif Persalinan Normal di Rumah Sakit Adven Manado Tahun 2014, Menunjukkan nyeri persalinan sebelum dilakukan massage counter pressure berada pada skala 9-10 (100\%) dan 
setelah dilakukan massage counter pressure nyeri menurun paling besar pada skala 3-6 sebanyak 13 responden $(86,7 \%)$, hal ini memberikan hasil bahwa massage counter pressure sangat efektif untuk mengurangi nyeri persalinan dan ada perbedaan yang signifikan antara sebelum dengan sesudah massage counter pressure (Pasongli, 2014).

Penelitian lainnya yang mendukung adalah penelitian yang dilakukan oleh Tuti Oktriani, Ermawati, Hafni Bachtiar dengan judul "The Difference Of Pain Labour Level With Counter Pressure And Abdominal Lifting On Primigravida In Active Phase Of First Stage Labor". Hasil penelitian menyatakan massage counter pressure lebih efektif mengatasi nyeri persalinan dengan uji statistik $p$ value 0,001 dibaningkan dengan teknik abdominal lifting yang hasil uji statistiknya $p$ value 0,015 .

Metode massage dapat menghasilkan penurunan nyeri, karena berdasarkan teori massage dapat mengaktivasi serat berdiameter besar yang akan menutup stimulus nyeri, selain itu massage dapat menghasilkan endorpin yang berguna mengurangi nyeri (Sari, 2015). Massage counter presurre merupakan pijatan menggunakan kepalan tangan pada daerah sacrum/lumbal atau pusat nyeri ibu bersalin (Marmi, 2016).

Teknik massage counter pressure selama persalinan akan membantu ibu bersalin meringankan kram dan ketegangan pada otot tulang paha maupun tulang panggul, menurunkan nyeri pinggang yang dirasakannya serta mampu mempercepat penurunan kepala bayi sehingga proses persalinan menjadi lebih cepat, dengan memberikan massage counter pressure tubuh akan memproduksi hormon endorphin yang dapat mengurangi nyeri pada ibu bersalin (Yuliatun, 2013).

Nyeri pada proses persalinan merupakan kondisi yang normal dialami oleh hampir semua ibu bersalin dengan tingkat nyeri berbeda pada masing-masing individu. Nyeri persalinan dapat diartikan sebagai tanda bahwa ibu telah memasuki tahapan pada persalinan. Rasa nyeri bersalin yang dirasakan oleh ibu bisa dipengaruhi oleh beberapa faktor diantaranya rasa takut, cemas, belum adanya persiapan, kurangnya dukungan dan pengalaman bersalin sebelumnya (Judha, 2012).

Menurut asumsi peneliti, penerapan metode massage counter pressure sangat berpengaruh terhadap intensitas nyeri pada ibu bersalin kala I fase aktif. Ibu yang memperoleh massage counter pessure akan merasakan dirinya menjadi lebih tenang, rileks, nyaman, dan akan merasa lebih dekat dengan orang yang melayaninya seperti petugas kesehatan sehingga tanpa disadari hal ini bisa meringankan intensitas nyeri yang dirasakan oleh ibu.

\section{PENUTUP}

\section{SIMPULAN}

1. Nyeri persalinan sebelum dilakukan massage counter 
pressure paling banyak responden mengalami nyeri berat yaitu sebanyak 9 orang $(60,0 \%)$.

2. Nyeri persalinan sesudah dilakukan massage counter pressure paling banyak responden mengalami nyeri sedang yaitu sebanyak 8 orang $(53,3 \%)$.

3. massage counter pressure efektif untuk menurunkan nyeri pada ibu bersalin kala I fase aktif dengan nilai uji statistik $\mathrm{p}=0,000$.

\section{SARAN}

1. Bagi Petugas Kesehatan

Diharapkan petugas kesehatan terutama bidan dapat memberikan massage counter pressure pada ibu bersalin agar dapat mengurangi angka morbiditas dan mortalitas pada ibu.

2. Bagi Pihak Kampus

Diharapkan institusi dapat menambah buku atau refensirefrensi guna mempermudah mahasiswa untuk melakukan penelitian.

3. Bagi Peneliti Selanjutnya

Semoga peneliti selanjutnya bisa menambah group control sehingga dapat lebih jelas melihat efektifitas massage counter pressure.

\section{DAFTAR PUSTAKA}

Afritayeni. (2017). Hubungan Umur, Paritas dan Pendamping Persalinan dengan Intensitas Nyeri Persalinan Kala I 2(2):178-185 http://garuda.ristekbrin.go.id/ documents/detail/854429 diakses tanggal 30 Desember 2020

Dinkes Provinsi Bali. (2020). Profil Kesehatan Provinsi Bali Tahun 2019. Bali: Dinkes Provinsi Bali. Diakses dari https://www.diskes.baliprov. go.id/download/profil-

kesehatan-2019/ tanggal 7

Oktober 2020

Farida, D. A., Kartika S. \& Puji L. (2017). Pengetahuan Bidan Tentang Teknik Massage Dengan Minat Penerapan Dalam Mengurangi Nyeri Persalinan.

http://repository2.unw.ac.id/ 774/1/PROSIDING\%20SE MINAR\%20NASIONAL\%2 $0 \% 20 \% 20 \% 20$ KEBIDANA N\%20DAN\%20CALL\%20F OR\%20PAPER.pdf diakses tanggal 17 November 2020

Judha, M., Sudarti \& Afroh F. (2012). Teori pengukuran Nyeri dan Nyeri Persalinan. Yogyakarta: Nuha Medika

Kemenkes RI. (2020). Profil Kesehatan Indonesia 2019. Jakarta: Kemenkes RI. Diakses dari https://www.kemkes.go.id/re sources/download/pusdatin/p rofil-kesehatanindonesia/Profil-KesehatanIndonesia-2019.pdf tanggal 7 Oktober 2020

Mahastuti, I G. A. A. E. \& Ninik C. (2017). Manfaat Metode Hypnobirthing Dalam Proses Persalinan.

http://repository2.unw.ac.id/ 774/1/PROSIDING\%20SE MINAR\%20NASIONAL\%2 $0 \% 20 \% 20 \% 20$ KEBIDANA N\%20DAN\%20CALL\%20F OR\%20PAPER.pdf diakses tanggal 17 November 2020

Marmi. (2016). Intranatal Care Asuhan Kebidanan Pada 
Persalinan. Yogyakarta: Pustaka Pelajar

Notoatmodjo, Soekidjo. (2012). Metodologi Penelitian Kesehatan. Jakarta: PT Asdi Mahastya

Nuriasih, Ai., Ani R. \& Dewi L.B. (2014). Asuhan Persalinan Normal Bagi Bidan. Bandung: PT Refika Aditama

Oktriani, T., Ermawati \& Hafni B. (2018). The Difference of Pain Labour Level With Counter Pressure And Abdominal Lifting On Primigravida In Active Phase Of First Stage Labor 3(2):4652.

http://jom.fk.unand.ac.id/ind ex.php/jom/article/view/79/5

3 diakses tanggal 29 Desember 2020

Sari, Kartika \& Ninik C. (2015). Musik dan Massage Dapat Mengurangi Nyeri Persalinan Kala I Ibu Primigravida. Jurnal Keperawatan Soedirman 10(2):203-209. http://jks.fikes.unsoed.ac.id/i ndex.php/jks/article/view/62 5/378 diakses tanggal 17 November 2020

Siregar, Diah P.S. (2019). Faktor Yang Mempengaruhi Ibu Bersalin Dalam Pemilihan Metode Pengurangan Nyeri Persalinan Di Klinik Pratama Anugrah Binjai Tahun 2019 2(1):95-105. http://midwifery.jurnalsenior .com/index.php/ms/article/vi ew/36/37 diakses tanggal 1 Januari 2020

Solehati, T. \& Cecep E. K. (2017). Konsep dan Aplikasi Relaksasi dalam Keperawatan Marenitas. Bandung: PT Rafika Aditama

Utami I. \& Enny F. (2019). Buku Ajar Asuhan Persalinan \& Managemen Nyeri Persalinan. Yogyakarta: UNISA

Yuliatun, Laily. (2013). Penanganan Nyeri Persalinan Dengan Metode Nonfarmakologi. Malang: Bayu Media Publishing 